\title{
O ALINHAMENTO DE ROCHAS ALCALINAS POÇOS DE CALDAS-CABO FRIO (RJ) E SUA CONTINUIDADE NA CADEIA VITÓRIA-TRINDADE
}

\author{
ANTÔNIO THOMAZ FILHO \& ANA LÚCIA RODRIGUES
}

\begin{abstract}
THE ALIGNMENT OF ALKALINE ROCKS FROM POÇOS DE CALDAS TO CABO FRIO (RJ) AND ITS CONTINUITY IN THE CADEIA VITO RIA-TRINDADE Geologic, geomorphologic and geochronologic evidences indicate that the WNW-ESE alignment of alkaline rocks between Poços de Caldas and Cabo Frio, in the State of Rio de Janeiro, emplaced during the displacement of the South American plate over a hot spot. During the Eocene, the hot spot probably arrived at the eastem limit (coast of Rio de Janeiro State) of the South American continent, and resulted in important tectonic and magmatic events. Associated to these events, occurred a relative displacement of the hot spot to the alignment of volcanic rocks of the Cadeia Vitória-Trindade along the oceanic zone. As a consequence the following events took place: (a) intense eocenic volcanism of the Plataforma de Cabo Frio and Arquipelago de Abrolhos; (b) opening of the tapnrogenic basins in the Brazilian Southeast (Taubaté, Resende, Volta Redonda, and others), about $40 \mathrm{Ma}$ ago; and (c) formation of eocenic unconformities and/or the contemporaneous volcanism in the sedimentary sequences of the marginal Brazilian basins of Pelotas, Santos, Campos, Espírito Santo, Cumuruxatiba and Jequitinhonha. Two important mprphologic features can be observed in the sense of reinforcing this intepretation. One is the pronounced inflection, to southwest, of the west Umit of the Cadeia Vitória-Trindade, in contrast to its preferential east-west direction along the oceanic zone. The other is the northeast alignment of the oil fields of the Campos Basin, the most important oil production Brazilian basin, that is in agreement with the proposed path of the hot spot.
\end{abstract}

Keywords: alkaline rocks, hot spots, tectonism, magmatism, heat flow

RESUMO Com base em algumas evidências geológicas, geomorfológicas e geocronológicas, propõe-se que o Alinhamento de Rochas Alcalinas Poços de Caldas-Cabo Frio, que se estende na direcão WNW-ESE, no Estado do Rio de Janeiro, tenha se implantado quando da passagem da placa litosférica Sul-Americana por sobre um hot spot. Durante o Éoceno, esse hot spot teria chegado ao limite leste do continente, ou seja, ao litoral do Estado do Rio de Janeiro, e foi acompanhado por importantes eventos tectônicos e magmáticos. Associado a esses eventos, teria ocorrido o deslocamento relativo do hot spot no sentido do alinhamento de rochas vulcânicas da Cadeia Vitória-Trindade. Como prováveis consequências desse tectonismo, dada a contemporaneidade, citam-se o intenso vulcanismo eocênico da Plataforma de Cabo Frio e do Arquipélago de Abrolhos; o início da formacão das bacias tafrogênicas do sudeste brasileiro (Taubaté, Resende, Volta Redonda e outras), o que ocorreu há pouco mais de 40 Ma; e as pronunciadas discordâncias sedimentares eocênicas e/ou os magmatismo contemporâneo observado nas sequências sedimentares das bacias marginais brasileiras de Pelotas, Santos, Campos, Espírito Santo, Cumuruxatiba e Jequitinhonha. Duas importantes feições morfológicas podem ser observadas no sentido de reforçar essa proposição. Uma delas diz respeito à pronunciada inflexão para sudoeste do limite oeste da Cadeia VitóriaTrindade, contrastando com sua direção preferencial leste-oeste, ao longo da zona oceânica. A outra, refere-se à tendência do alinhamento no sentido nordeste dos campos de petróleo da Bacia de Campos, a mais importante bacia produtora de petróleo do Brasil, coincidente com a direção proposta para o "caminhamento" do hot spot.

Palavras-chave: rochas alcalinas, hot spots, tectonismo, magmatismo, fluxo de calor

INTRODUÇÃO O Alinhamento de Rochas Alcalinas Poços de Caldas-Cabo Frio (Freitas 1947, Almeida 1983,1986,1991,eAlmeida et al. 1996) compreende uma sequência de eventos vulcânicos localizados, representados por rochas alcalinas que formam stocks, plugs, possíveis chaminés, diques e excepcionalmente derrames e piroclásti-cas. Essas rochas apresentam idades variando do Cretáceo Superior ao Eoceno e se alinham numa direção WNW-ESE, no Estado do Rio de Janeiro, e cortam, de forma oblíqua, a direção preferencial das estruturas tectônicas da Faixa Orogênica Ribeira, de idade pré-cambriana a cambriana. Almeida (1991) refere-se a essas rochas alcalinas corno sendo predominantemente félsicas e representadas principalmente por nefelina sienito, pulaskito, foiaíto, fonólito, tinguaíto e traquito. Inúmeros estudos têm procurado interpretar a origem desse alinhamento de corpos de rochas preferencialmente alcalinas. Alguns deles, como Herz (1977), Cordani \& Teixeira (1979), Sadowski \& Dias Neto (1981), Fletcher \& Litherland (1981), Fodor et al. (1983/1984), e Gibson et al. (1995 e 1997) sugeriram tratar-se de manifestações magmáticas periódicas, quando da movimentação da placa litosférica Sul-Americana por sobre um hot spot situado possivelmente na astenosfera, durante a fase de separação entre as placas tectônicas da América do Sul e da África.

O presente estudo objetivou pesquisar evidências geológicas, geomorfológicas e geocronológicas que viessem a trazer alguns subsídios para elucidar a questão. Como as informações disponíveis favoreceram a hipótese de tratar-se realmente de um hot spot, ampliou-se o estudo no sentido de verificar a continuação desse alinhamento vulcânico ao longo da crosta oceânica desenvolvida após o rifteamento continental, procurando identificar possíveis eventos tectônicos associados. Ao mesmo tempo, e por extensão do propósito, abriram-se as perspectivas do estudo de uma possível interferência desse hot spot na ocorrência de petróleo nas bacias sedimentares marginais da costa sudeste brasileira, em particular na Bacia de Campos. As informações obtidas neste trabalho propiciaram interessantes observações que trazem subsídios para respostas a essas importantes questões.

MÉTODOS DE TRABALHO Uma ampla pesquisa bibliográfica forneceu as informações disponíveis sobre a tectônica fanerozóica e 0 magmatismo a ela associado no Estado do Rio de Janeiro. A partir dessas informações, elaborou-se a integracão de três mapas: 1) Mapa Geoló gico do Projeto RADAMBRASIL (1983), na escala de 1: 1.000 .000 , de onde foram destacadas as localizações das rochas alcalinas do Alinhamento Poços de Caldas-Cabo Frio, das quais se têm informações geocronológicas; 2) Mapas Fisiográfico e Batimétrico da margem continental leste do Brasil (1979), na escala de 1:3.500.000, do Projeto Reconhecimento da Margem Continental Brasileira (REMAC); e 3) Mapa de localização dos campos de petróleo da Bacia de Campos. A partir dessa integração, elaborou-se o mapa mostrado na figura 1 , na escala aproximada de 1:6.000.000.

Seguiu-se o levantamento bibliográfico das idades radiométricas, pelo método Potássio/Argônio, das rochas alcalinas do alinhamento Poços de Caldas-Cabo Frio, da Plataforma de Cabo Frio e do Arquipélago de Abrolhos. A análise criteriosa das idades publicadas, levando em consideração as mais confiáveis (resultantes de plagioclásio, biotita, anfibólio e rocha total) e descartando as de significado mais duvidoso (resultantes de piroxênios, feldspatos potássicos e feldspatos indeterminados), permitiu elaborar uma média mais confiável das idades obtidas, ate o presente, para essas diferentes manifestações (Tabela 1). As médias das idades, conforme mostrado na figura 2 , indicaram um consistente decréscimo de valores, na medida que caminham de oeste para leste, ou seja de Poços de Caldas para Cabo Frio.

Na busca de evidências tectônicas que teriam se manifestado nesse período, foram analisadas as colunas estratigráficas das bacias sedimentares da margem continental sudeste brasileira (Fig. 3).

DISCUSSÃO Amaral et al. (1967) e Almeida (1983), abordando as rochas alcalinas mesozóicas da região meridional da Plataforma SulAmericana, identificaram duas fases desse magmatismo: a primeira, contemporânea aos basaltos da Bacia do Paraná, ocorrendo nas bordas dessa bacia; e a segunda, com início no Cretáceo Superior (Cenomaniano) e com derradeira manifestação no Terciário Inferior (Eoceno). Nesta última fase concentra-se o presente estudo.

Cordani \& Teixeira (1979), ao analisarem as ocorrências de rochas alcalinas no Estado do Rio de Janeiro, observaram a tendência de idades decrescentes do maciço de Marapicu (Município de Nova Iguaçu - RJ) até Cabo Frio, ou seja, de oeste para leste. Sugeriram tratar-se de episódios magmáticos sucessivos, ligados geneticamente, o que implicaria em admitir-se um movimento da litosfera, de leste para oeste, por sobre um hot spot da astenosfera, durante o período de 72 a 50 Ma.

* Universidade do Estado do Rio de Janeiro - UERJ, Faculdade de Geologia, Rua São Francisco Xavier, 524 / $4^{\circ}$ andar / sala 4030, Maracanã - CEP $20559-900$ - Rio de Janeiro - RJ, Tel. (021) 587-7102; FAX (021) 587-7704 ; (021) 254-6675, E-mail: thomaz@uerj.br 


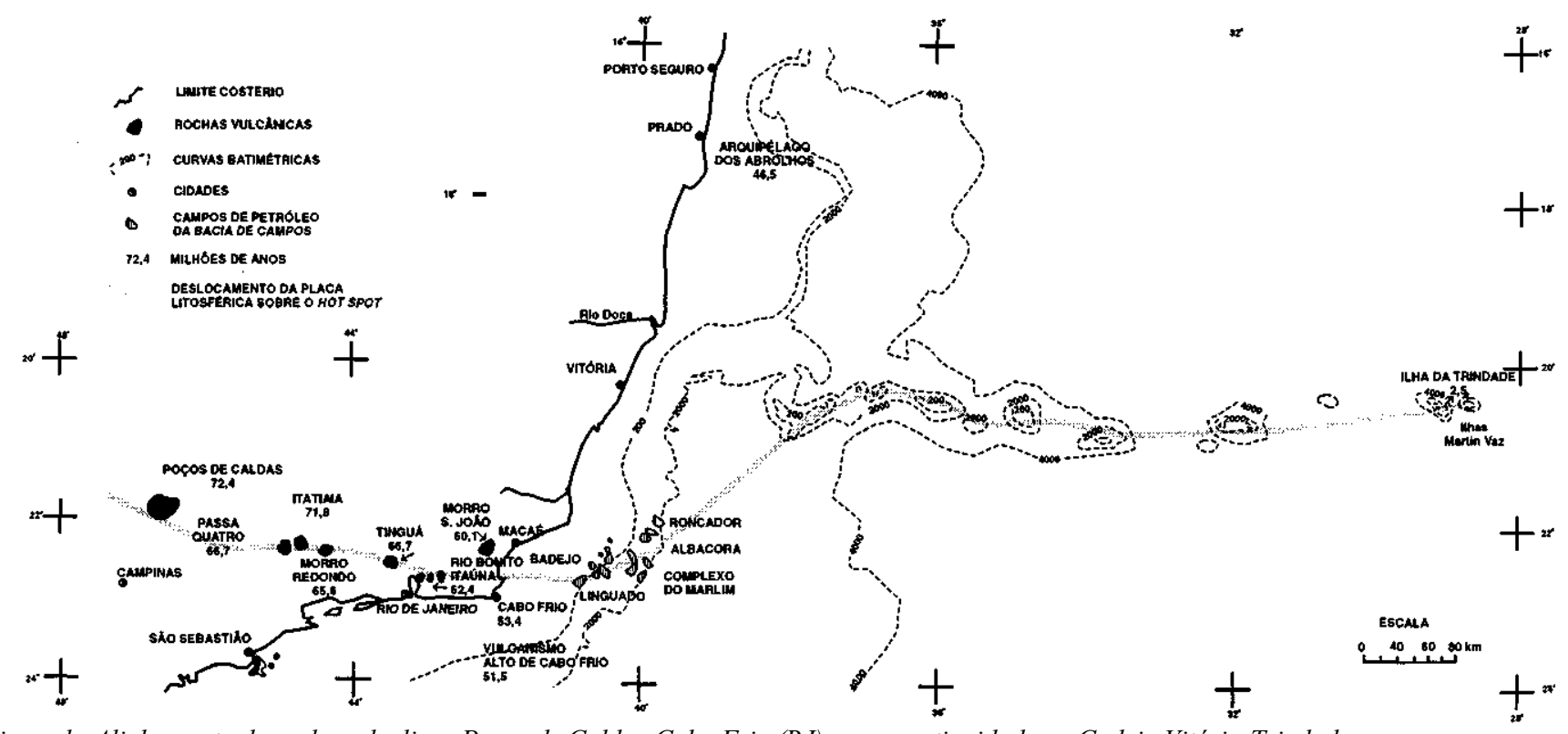

Figura l-Alinhamento de rochas alcalinas Poços de Caldas-Cabo Frio (RJ) e sua continuidade na Cadeia Vitória-Trindade

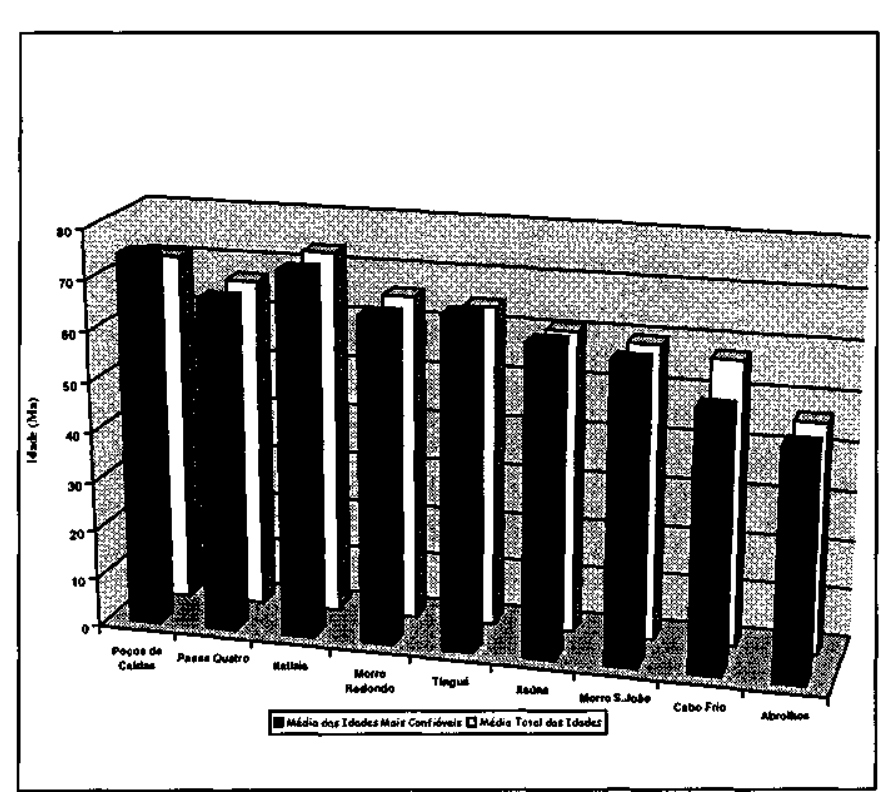

Figura 2 - Distribuição das idades radiométricas $K / A r$ das rochas alcalinas do Alinhamento Poços de Caldas-Cabo Frio

Considerando o consistente decréscimo de valores das idades das rochas alcalinas, na medida em que se caminha de oeste para leste (Fig. 2), não há como deixar de admitir a possibilidade de tratar-se de manifestações periódicas de um hot spot, quando da movimentação no sentido leste da placa litosférica Sul-Americana, após o rifteamento continental América do Sul/África. Convém salientar que Herz (1977) já havia interpretado a ocorrência dessas manifestações alcalinas como produto do deslocamento da placa litosférica sobre hot spots fixos no manto. Isso teria ocorrido ao longo da faixa litorânea, com início há cerca de $82 \mathrm{Ma}$, na região de São Sebastião (SP), com pronunciada manifestação, há cerca de $51 \mathrm{Ma}$, na região de Cabo Frio (RJ) (Amaral et al. 1967, Almeida et al. 1996), e com movimento relativo, nos últimos $51 \mathrm{Ma}$, inferido pelo alinhamento dos montes submarinos que constituem a Cadeia Vitória-Trindade. No presente trabalho, propõe-se que o hot spot que deu origem a essa cadeia teve, na realidade, movimento relativo da placa litosférica Sul-Americana por sobre um hot spot situado ao longo ao alinhamento Poços de Caldas-Cabo Frio, como sugerido por Sadowski \& Dias Neto (1981). Estes últimos autores, ao analisarem a posição dos continentes, reconstruindo seus movimentos de rotação inversa até chegar-se à junção das placas litosféricas, verificaram que o alinhamento Poços de Caldas-Cabo Frio coincide adequadamente com a trajetória referente à posição do pólo de rotação, durante o período de 84 a 49 Ma (Almeida 1991). Essa interpretação encontra suporte nos estudos realizados por Gibson et al. (1995 e 1997), quando se referem ao impacto de uma pluma mantélica a que denominaram Trindade, no Cretáceo Superior, nas regiões oeste, central e sudeste do Brasil. O calor gerado por esta pluma teria propiciado a fusão, em larga escala, de parte do manto litosférico subcontinental. Concluem os referidos autores que a estreita cadeia de ilhas oceânicas e montes submarinos que culmina, a leste, com as ilhas de Trindade e Martin Vaz, seria o resultado do traçado de um hot spot desenvolvido nas bordas da pluma mantélica de Trindade.

No mapa da figura 1, observa-se que o vulcanismo do Alto de Cabo Frio e do Arquipélago de Abrolhos ocorreu aproximadamente entre 45 e 55 Ma (Cordani 1970, Cordani \& Blazekovic 1970), ou seja, no Eoceno Inferior, quando o hot spot teria atingido a margem leste continental. Esse vulcanismo, representado por edifícios vulcânicos que ocorrem na borda do continente Sul-Americano e na plataforma continental do sudeste do Brasil, é testemunho da grandeza desse evento e foi objeto de estudo de Szatmari \& Mohriak (1995) que, ao interpretarem os eventos tectônicos maiores nos Andes Central, reportam a fase orogênica Inça, ocorrida no Eoceno-Oligoceno (com início há 42 Ma), como contemporânea ao magmatismo da margem leste brasileira. Datações por traços de fissão realizadas por Fonseca et al. (1992) em titanita e apatita de rochas da região de Cabo Frio e Búzios (RJ) indicaram dois conjuntos de idades: cerca de 40 Ma e cerca de $190 \mathrm{Ma}$, ambos relacionados a aquecimentos crustais. O primeiro conjunto é contemporâneo com as intrusões das rochas alcalinas que ocorrem naquela região.

A figura 1 revela pelo menos dois aspectos que merecem análise mais detalhada. Um diz respeito à pronunciada inflexão para sudoeste do limite oeste da Cadeia Vitória-Trindade. O outro refere-se ao alinhamento no sentido nordeste dos campos de petróleo da Bacia de Campos, coincidente com a direção preferencial do trajeto de uma linha imaginária ligando a tendência da referida inflexão com a provável chegada do hot spot na margem continental leste brasileira, ou seja, na região de Cabo Frio (RJ). Cones vulcânicos submarinos, representados por rochas alcalinas, são observados na plataforma continental leste brasileira (Almeida 1991, Vieira et al. 1987). Estes últimos autores, baseados em mapeamento gravimétrico, verificaram uma anomalia junto à charneira da Bacia de Campos, aproximadamente a $90 \mathrm{~km}$ a ENE de Cabo Frio, atribuída à provável intrusão de rochas alcalinas. Através de perfis sísmicos de reflexão e de dados de poços, Mohriak et al. (1990, 1991), Mizusaki \& Mohriak (1992) e Mizusaki et al. (1994) identificaram a ocorrência de edifícios vulcânicos na plataforma continental, entre as bacias de Campos e Santos, e concluíram que esse vulcanismo é de idade eocênica, ou seja, pós-rifte; apresenta tendência marcadamente alcalina; e está associado a rochas vulcanoclásticas. Gamboa \& Rabinowitz (1984) também se referem ao grande volume de rochas vulcânicas piroclásticas e cones vulcâni- 

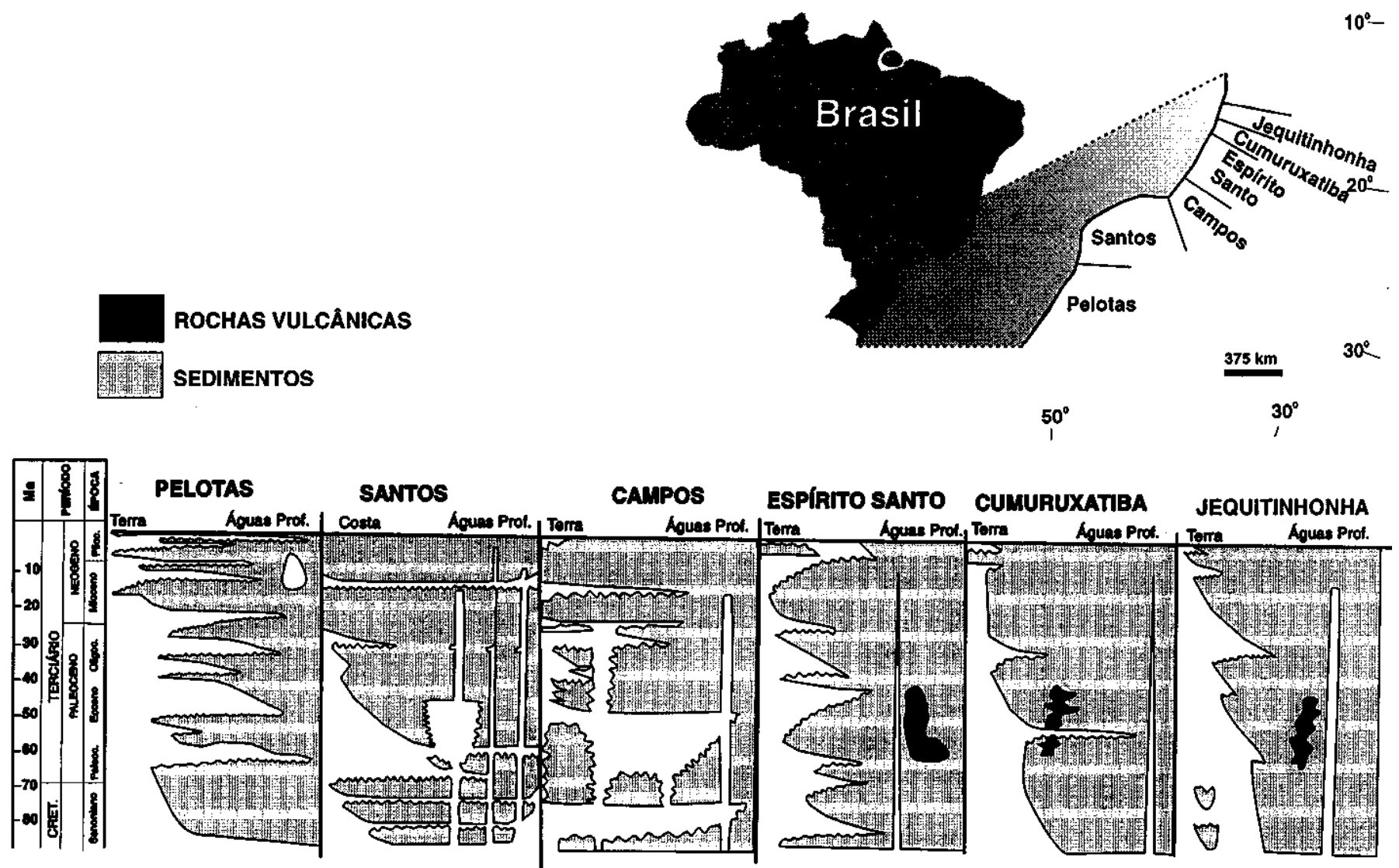

Figura 3 - Sedimentação em águas rasas e profundas das bacias de Pelotas, Santos, Campos, Espírito Santo, Cumuruxatiba e Jequitinhonha (Boi de Geociencias da PETROBRAS 1994, $n^{\circ}$ 1, vol. 8)

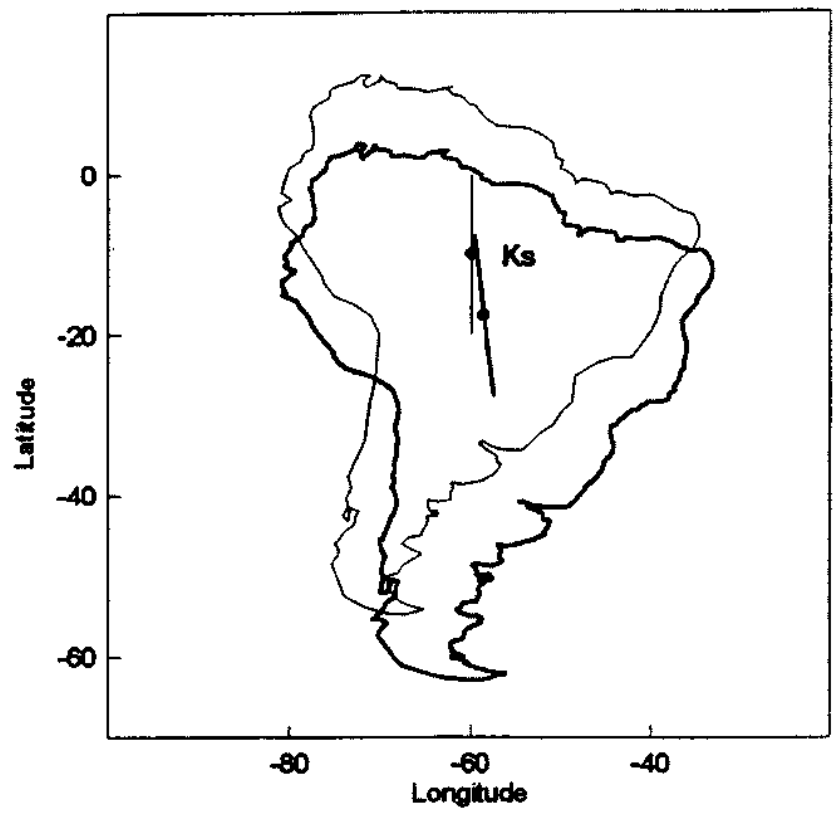

Figura 4 - Deslocamento da placa litosférica Sul-Amerícana, do Cretáceo Superior ao tempo presente, baseado em estudos paleomagnéticos (Ernesto 1996)

cos, de idade eocênica (50 Ma), observados em linhas de reflexão sísmica na área entre as bacias de Santos e Campos.

Essas evidências levam a admitir que o hot spot alimentador das manifestações alcalinas entre Poços de Caldas e Cabo Frio pode ter-se deslocado, de forma relativa, a partir de Cabo Frio, no sentido nordeste, e ter sua continuação ao longo da Cadeia Vitória-Trindade. No proc- esso, teria passado por sob os sedimentos da Bacia de Campos e estaria, hoje, situado nas proximidades das ilhas de Trindade e Martins Vaz, onde ocorrem intrusivas fonolíticas, além de diques básicos e ultrabásicos, formando o que Cordani (1970) denominou de Complexo de Trindade, com idades K/Ar entre 2,9 e 2,3 Ma. Muito provavelmente aqui está a explicação para o fato de Almeida (1986) ter observado que o alinhamento de ilhas oceânicas vulcânicas da Cadeia Vitória-Trindade se estende claramente até o talude continental, não tendo sido observado, até o momento, seu possível prolongamento na área continental emersa.

Por outro lado, considerada a hipótese dos hot spots serem pontos fixos na astenosfera, é lícito admitir-se que houve, de fato, um pronunciado deslocamento da placa litosférica Sul-Americana, no sentido sudoeste, durante o Eoceno. Com relação a este último aspecto, é oportuno referir-se às conclusões a que chegou Ernesto (1996), quando da reconstrução das movimentações da placa litosférica Sul-Americana, de acordo com as rotações sugeridas pelos posicionamentos dos pólos magnéticos para diferentes idades, mostrando que a placa teria sofrido uma rotação horária significativa do Cretáceo Superior até a sua posição atual (Fig. 4). É provável que substancial parte dessa rotação tenha, de fato, ocorrida no Eoceno, associada ao intenso tectonismo e magmatismo manifestados no mesmo período.

Esse notável deslocamento da placa litosférica Sul-Americana, durante o Eoceno, encontra suporte em alguns eventos de caráter muito mais abrangente no nosso planeta. Pode-se citar a significativa mudança de direção entre as cadeias de rochas vulcânicas oriundas de hot spot do Imperador e do Hawai, no noroeste do Oceano Pacífico, ocorrida há cerca de $45 \mathrm{Ma}$ (Skinner \& Porter 1992).

No início do Terciário ou, mais precisamente, no Eoceno (Almeida 1976, Hasui et al. 1978, Riccomini et al. 1989, Melo et al. 1985, Azevedo Júnior 1991), iniciaram-se a formação, por movimentos tectônicos, e a sedimentação ativa nas bacias tafrogênicas do sudeste brasileiro, tais como as bacias de São Paulo, Taubaté, Resende, Volta Redonda, Barra de São João, que se alinham e se encaixam em depressões alongadas no sentido nordeste, ao longo do Cinturão Orogênico Ribeira. Seriam contemporâneos a esse tectonismo os 
Tabela l-Idades radiométricas K/Ar das rochas alcalinas do Alinhamento Poços de Caldas-Cabo Frio (Sonoki \& Garda 1988, Cordani 1970, Ribeiro-Filho \& Cordani 1966, Amaral et al. 1967)

\section{IDADES RADIOMÉTRICAS K/AR DAS ROCHAS ALCALINAS DO ALINHAMENTO POÇOS DE CALDAS-CABO FRIO}

(SONOKI \& GARDA, 1988; CORDANI, 1970; AMARAL et al., 1967; RIBEIRO FILHO \& CORDANI, 1966)

\begin{tabular}{|c|c|}
\hline \multicolumn{2}{|c|}{ Poços de Caldas } \\
\hline Idade (Ma) & Material \\
\hline 82,3 & Biotita \\
\hline 82,7 & Biotita \\
\hline 76,9 & Rocha total \\
\hline 75,0 & Rocha total \\
\hline $65,4 \pm 1,6$ & Rocha total \\
\hline 64,3 & Rocha total \\
\hline 66,0 & Rocha total \\
\hline 89,3 & Rocha total \\
\hline 78,4 & Rocha total \\
\hline 77,1 & Rocha total \\
\hline 77,3 & Rocha total \\
\hline 82,0 & Rocha total \\
\hline 82,4 & Rocha total \\
\hline 82,2 & Rocha total \\
\hline 76,0 & Rocha total \\
\hline 75,7 & Rocha total \\
\hline 74,9 & Rocha total \\
\hline 71,1 & Rocha total \\
\hline 74,5 & Rocha total \\
\hline 74,2 & Rocha total \\
\hline 65,4 & Rocha total \\
\hline 63,6 & Feldsp. $K$ \\
\hline 61,2 & Feldsp. $K$ \\
\hline 61,7 & Feldsp. $K$ \\
\hline 62,3 & Feldsp. $K$ \\
\hline 54,2 & Rocha total \\
\hline $85,5 \pm 15,1$ & Piroxênio * \\
\hline $86,5 \pm 1,2$ & Rocha total \\
\hline $75,4 \pm 3,0$ & Antib6lio \\
\hline $82,5 \pm 6,6$ & Anfibólio \\
\hline $78,2 \pm 1,8$ & Feldspato \\
\hline $75,5 \pm 1,4$ & Feldspato \\
\hline $72,4 \pm 1,3$ & Feldspato \\
\hline $78,0 \pm 1,3$ & Rocha total \\
\hline $81,0 \pm 1,0$ & Roche total \\
\hline $\begin{array}{l}66,3 \pm 4,0 \\
66,2 \pm 2,0\end{array}$ & $\begin{array}{c}\text { Rocha total } \\
\text { Anfibólio }\end{array}$ \\
\hline $\begin{array}{r}71,7 \pm 2,5 \\
54,3 \pm 1,7\end{array}$ & $\begin{array}{l}\text { Feldspato } \\
\text { Anfibólio }\end{array}$ \\
\hline $\begin{array}{l}\text { Média total: } \\
\text { Média mais con }\end{array}$ & $\begin{array}{l}70,7 \mathrm{Ma} \\
74,6 \mathrm{Ma}\end{array}$ \\
\hline
\end{tabular}

\begin{tabular}{|c|c|}
\hline \multicolumn{2}{|c|}{ Pasara Quatro } \\
\hline Idades (Ma) & Material \\
\hline $66,7 \pm 3,3$ & Anfibólio \\
\hline \multicolumn{2}{|c|}{ Itatiada } \\
\hline Idades (Ma) & Material \\
\hline 68,8 & Blotita \\
\hline 67,8 & Biotita \\
\hline 67,9 & Anfibolio \\
\hline 68,4 & Blotita \\
\hline $66,4 \pm 2,5$ & Blotita \\
\hline $\begin{array}{c}65,7 \\
79,5 \pm 1,0\end{array}$ & Biotita \\
\hline $74,9 \pm 2,1$ & Blotita \\
\hline $74,1 \pm 1,0$ & Biotita \\
\hline $73,3 \pm 1,0$ & Nefelina \\
\hline $71,2 \pm 1,5$ & Biotita \\
\hline $73,6 \pm 1,0$ & Blotita \\
\hline $90,5 \pm 2,2$ & Plaglocásio \\
\hline $77,1 \pm 1,1$ & Feldsp. $K$ \\
\hline $\begin{array}{l}90,5 \pm 2,2 \\
64,6 \pm 1,0\end{array}$ & $\begin{array}{c}\text { Biotita } \\
\text { Rocha total }\end{array}$ \\
\hline Média total: & $73,4 \mathrm{Ma}$ \\
\hline \multicolumn{2}{|c|}{ Media mais confinfvel: } \\
\hline \multicolumn{2}{|c|}{ Morro Redondo } \\
\hline Idades (Ma) & Material \\
\hline 65,6 & Anfibólio \\
\hline \multicolumn{2}{|c|}{ Tinguh } \\
\hline Idades (Ma) & Material \\
\hline $60,1 \pm 3,9$ & Máficos \\
\hline $67,9 \pm 2,6$ & Blotita \\
\hline $\begin{array}{c}39,1 \pm 3,4 \\
65,5\end{array}$ & $\begin{array}{l}\text { Rocha total* } \\
\text { Antibóliso }\end{array}$ \\
\hline $\begin{array}{l}\text { Média total: } \\
\text { Módia mais conf }\end{array}$ & $\begin{array}{l}64,5 \mathrm{Ma} \\
66,7 \mathrm{Ma}\end{array}$ \\
\hline
\end{tabular}

*Dado não utilizado na média 
Tabela J-Continuação

\section{IDADES RADIOMÉTRICAS K/AR DAS ROCHAS ALCALINAS DO ALINHAMENTO POÇOS DE CALDAS-C ABO FRIO}

(SONOKI Os GARDA, 1988; CORDANI, 1970; AMARAL et al., 1967; RIBEIRO PILHO \& CORDANI, 1966)

\begin{tabular}{c|c}
\hline \multicolumn{2}{c}{ Itaúna } \\
\hline Idades (Ma) & Material \\
\hline $50,9 \pm 1,6$ & Feldsp. $K$ \\
$62,4 \pm \mathbf{1 , 7}$ & Rocha total \\
$69,4 \pm 2,2$ & Feldsp. $K$ \\
\hline Média total: & $60,9 \mathrm{Ma}$ \\
\hline Média mais confível: & $\mathbf{6 2 , 4} \mathbf{M a}$ \\
\hline
\end{tabular}

\begin{tabular}{c|c}
\hline \multicolumn{2}{c}{ Rio Bonito } \\
\hline Idades (Ma) & Material \\
\hline 72,2 & Feldsp. $K$ \\
75,9 & Feldsp. $K$ \\
83,9 & Feldsp. $K$ \\
69,7 & Feldsp. $K$ \\
\hline Media total: & $75,4 \mathrm{Ma}$ \\
\hline Media mais confiável: & \\
\hline
\end{tabular}

\begin{tabular}{c|c}
\hline \multicolumn{2}{c}{ Morro s5o Joho } \\
\hline Idadea (Ma) & Material \\
\hline 60,1 & Rocha total \\
58,7 & feldspato \\
\hline Media total: & $59,4 \mathrm{Ma}$ \\
\hline Media mais confisvel: & $60,1 \mathrm{Ma}$ \\
\hline
\end{tabular}

\begin{tabular}{c|c}
\hline \multicolumn{2}{c}{ Cabo Frio } \\
\hline Idades (Ma) & Material \\
\hline $72,4 \pm 2,9$ & Feldsp. $K$ \\
$52,6 \pm 2,0$ & Rocha total \\
$54,5 \pm 2,6$ & Biotita \\
$\mathbf{5 0 , 0}$ & Rocha total \\
\hline Média total: & $57,4 \mathrm{Ma}$ \\
\hline Média mais conflävel: & $\mathbf{5 2 , 3} \mathbf{M a}$ \\
\hline
\end{tabular}

Significado duvidoso:

Piroxênio, Feldspato potássico e Feldspato (?)

depósitos sedimentares das regiões de Itaguaí e Itaboraí, no chamado Rifte da Guanabara (Mohriak et al 1991, Ferrari 1990).

Riccomini et al (1983 e 1991) verificaram a ocorrência de lavas ankaramíticas (com estrutura amigdaloidal) intercaladas em depósitos de fanglomerados da Formação Resende, da Bacia de Volta Redonda, com idade próxima de $42 \mathrm{Ma}$, ou seja, do Eoceno Superior e consideraram essa a idade de formação dessa bacia e de suas correlatas. Rochas vulcânicas de natureza similar e muito provavelmente sincrônicas foram observadas na Depressão da Guanabara, mais especi-

\begin{tabular}{|c|c|}
\hline \multicolumn{2}{|c|}{ Abrolhos } \\
\hline Idades (Ma) & Material \\
\hline $43,3 \pm 1,3$ & Rocha total \\
\hline $41,4 \pm 1,2$ & Plagioclasto \\
\hline $46,6 \pm 4,7$ & Roeha total \\
\hline $52,4 \pm 1,6$ & Rocha total \\
\hline $50,3 \pm 2,0$ & Rocha total \\
\hline $47,6 \pm 1,5$ & Rocha total \\
\hline $44,1 \pm 3,5$ & Plagioclásto \\
\hline $63,6 \pm 7,0$ & Rocha total \\
\hline $64,5 \pm 5,8$ & Rocha total \\
\hline $38,9 \pm 2,3$ & Plagioclásio \\
\hline $46,2 \pm 6,5$ & Rocha total \\
\hline $43,4 \pm 3,5$ & Rocha total \\
\hline $52,4 \pm 1,7$ & Rocha total \\
\hline $32,2 \pm 1,9$ & Rocha Total \\
\hline $42,1 \pm 3,8$ & Rocha total \\
\hline $37,3 \pm 2,2$ & Rocha total \\
\hline $37,1 \pm 4,8$ & Plagloclásio \\
\hline $60,7 \pm 9,1$ & Rocha total \\
\hline $50,3 \pm 2,0$ & Rocha total \\
\hline $46,6 \pm 3,7$ & Rocha total \\
\hline $47,6 \pm 1,5$ & Rocha total \\
\hline $43,5 \pm 2,5$ & Rocha total \\
\hline $41,4 \pm 1,2$ & Plagiocianio \\
\hline $43,3 \pm 1,3$ & Rocha total \\
\hline Média total: & $46,5 \mathrm{Ma}$ \\
\hline Mótla mais conf & 46,5 Ma \\
\hline
\end{tabular}

Idades menos confiáveis

Idades mais confiáveis

Significado mais confiável:

Plagioclásio, Biotita, Anfibólio e Rocha Total

ficamente em São José de Itaboraí (Rodrigues et al 1982, Klein \& Valença 1984). Estes últimos autores compararam as vulcânicas de São José de Itaboraí às de Volta Redonda, dando-lhes como origem as movimentações rápidas de blocos e aos consequentes espasmos efusivos de câmaras magmáticas. Assim, tudo indica que, durante o Paleoceno, ocorreu uma reativação das zonas de cisalhamento do Ciclo Brasiliano/Pan-Africano, ao longo da Faixa Orogênica Ribeira, o que teria levado à formação das referidas bacias tafrogênicas (Riccomini et al 1991) e à das rochas vulcânicas alcalinas. 
Da mesma forma, Almeida (1983) refere-se ao magmatismo alcalino como o evento que precedeu ao desenvolvimento do sistema de rifles terciários da região meridional da Plataforma Sul-Americana, que teria se iniciado no Eoceno Inferior. Segundo Almeida (1976 e 1986), esse evento tectono-magmático teria ocorrido em período correlato com a mais acentuada subsidência da Bacia de Santos e 0 pronunciado soerguimento da região abrangida pela Serra do Mar (onde se desenvolveram os riftes), propiciando um desnível aproximado de $11 \mathrm{~km}$.

$\mathrm{Na}$ figura 3, estão colocadas as colunas estratigráficas das bacias de Pelotas, Santos, Campos, Espírito Santo, Cumuruxatiba e Jequitinhonha. Como evidências de importante tectonismo que teria afetado a evolução sedimentar dessas bacias, durante o Eoceno, podem ser observada, as marcantes discordâncias sedimentares ou, então, as significativas manifestações magmáticas denunciadoras de eventos tectônicos associados provavelmente a soerguimento e consequente processos de erosão dos sedimentos até então depositados.
CONCLUSÕES As informações obtidas neste trabalho levam a concluir que o alinhamento de rochas alcalinas Poços de Caldas-Cabo Frio, nos Estados de Minas Gerais e Rio de Janeiro, deve ter sido produto da passagem da placa litosférica Sul-Americana por sobre um hot spot situado possivelmente na astenosfera. Além disso, apontam para um importante deslocamento para NE desse hot spot, durante o Eoceno, acompanhado por intensas manifestacõos tectônicas e magmáticas, e sua provável continuidade ao longo da Cadeia Vitória-Trindade. As evidências aqui apresentadas assinalam pelas perspectivas de ser muito mais importante do que se pensava antes o efeito da passagem de uma bacia sedimentar por sobre um hot spot, nos processos da geração (maturação da matéria orgânica) e acumulação (modificacões estruturais) de petróleo nas bacias sedimentares marginais do sudeste do Brasil. Abrem-se, assim, as perspectivas de estudos mais aprofundados sobre a influência do fluxo de calor gerado pela passagem de hotspots sob as bacias sedimentares marginais brasilerras, nos processos de maturação da matéria orgânica geradora de hidrocarbonetos.

\section{Referências}

Almeida, F.F.M. 1976. The system of Continental Rift bordering the Santos Basin, Brazil. An. Acad. Bros. Cienc., 48 (Supl.): 15-26

Almeida, F.F.M. 1983. Relações tectônicas das rochas alcalinas mesozóicas da região meridional da Plataforma Sul-Americana. Revista Brasileira de Geociências, 13 (3): $139-158$

Almeida, F.F.M. 1986. Distribuição regional e relações tectônicas do magmatismo pós-paleozóico no Brasil. Revista Brasileira de Geociências, 16 (4): 325-349

Almeida, F.F.M. 1991. O alinhamento magmático de Cabo Frio. In: SBG/Núcleos São Paulo e Rio de Janeiro, $2^{\circ}$. Simp. Geol. Sudeste, Atas, 423-428

Almeida, F.F.M.; Carneiro, C.D.R.; Mizusaki, A.M.P. 1996. Correlação do magmatismo das bacias da margem continental brasileira com o das áreas emersas adjacentes. Revista Brasileira de Geociências, 26 (3): 125-138;

Amaral, G.; Bushee, J.; Cordani, U.G.; Kawashita, K.; Reynolds, J.H. 1967. Potassium-argon ages of alkaline rocks from southern Brasil. Geoch. et Cosmoch. Acto, 31: 117-142

Azevedo Júnior M.R. 1991. Integração entre o preenchimento sedimentar cenozóico das bacias de Campos e Santos e a evolução tectônica e geomorfológica das áreas continentais adjacentes - Escola de Minas da Universidade Federal de Ouro Preto, Ouro Preto, Minas Gerais, Dissertação de Mestrado, 160 p. Boletim de Geociência

da PETROBRÁS, 1994. Rio de Janeiro, 8 (1), 249 p.

Cordani, U.G. 1970. Idade do vulcanismo no Oceano Atlântico Sul. Boi. IGA, 1: 9-75

Cordani, U.G. \& Blazekovic, A. 1970. Idades radiométricas das rochas vulcânicas dos Abrolhos - In: SBG/Núcleo Brasília, Congresso Brasileiro de Geologia, 24, Brasília, Anais. 265-270

Cordani, U.G.; Teixeira, W. 1979. Comentários sobre as determinações geocronológicas existentes para as regiões das folhas Rio de Janeiro, Vitória e Iguapé. Carta Geológica do Brasil ao Milionésimo, folhas Rio de Janeiro (SF.23), Vitória (SF.24) e Iguapé (SF.23), MME, DNPM, Apêndice 1,175-207

Ernesto, M. 1996. Determinação da curva de deriva polar aparente para o Mesozóico da América do Sul. Instituto Astronómico e Geofísico, Universidade de São Paulo, São Paulo, Tese de Livre Docência, $56 \mathrm{p}$

Ferrari, A.L. 1990. A geologia do "rift" da Guanabara (RJ) da sua porção centro-ocidental e sua relação com o embasamento Pré-Cambriano. In: SBG, Congresso Brasileiro de Geologia, 36, Natal, RN, Anais, 6: 2858-2871

Fodor, R. V., Mckee, E.H.; Asmus, H.E. 1983/1984. K-Ar ages and the opening of the South Atlantic Ocean: basaltic rock from the brasilian margin - Marine geology, 54: M1-M8

Fonseca, A.C.; Bigazzi, G.; Cordani, U.G. 1992. Datação pelo método dos traços de fissão de algumas rochas de região entre Cabo Frio e Búzios. In: SBG, Congresso Brasileiro de Geologia, 37, São Paulo, Bol.Res Expandidos, 2: 190

Freitas, R.O. 1947. Jazimentos de rochas alcalinas da ilha de São Sebastião. São Paulo, Fac. Fil. Ciên. Letras, Boletim 85, Geologia 3, 244 p.

Fletcher, C.J.N.; Litherland, M. 1981. The geology and tectonic setting of the Velasco alkaline province, eastern Bolívia. Journal Geological Society of London, 138 (5): 541-548

Gamboa, L.A.P.; Rabinowitz, P.D. 1984. The evolution of the Rio Grande Rise in the southwest Atlantic Ocean. Marine Geology, 58: 35-38

Gibson, S.A.; Thompson, R.N.; Leonardos, O.H.; Dickin, A.P.; Mitchell, J.G. 1995. The Late Cretaceous impact of the Trindade mantle plume: evidence from large-volume, mafic potassic magmatism in SE Brazil. Journal Petrol, 36: 189-229

Gibson, S.A.; Thompson, R.N.; Weska, R.K.; Dickin, A.P.; Leonardos, O.H. 1997. Late Cretaceous rift-related upwelling and melting of the Trindade starting mantle plume head bebeath western Brazil - Contr. Mineral Petrol, 126: 303-314

Hasui, Y.; Almeida, F.F.M.; Neves, B.B. de B. 1978. As estruturas Brasilianas. In: SBG, Congresso Brasileiro de Geologia, 30, Recife, Anais, V.G.
Herz N. 1977. Timing of spreading in the South Atlantic: Information from Brasilian alkalic rocks -Geological Society of America Bulletin, 88: 101-112

Klein, V.C.; Valença, J.G. 1984. Estruturas almofadadas em derrame ankaramítico na Bacia de São José de Itaborá, Rio de Janeiro -In: SBG, Congresso Brasileiro de Geologia, 33, Rio de Janeiro, 4335-4345

Melo, M.S.; Riccomini, C.; Hasui, Y; Almeida, F.F.M.; Coimbra, A.M. 1985. Geologia e evolução do sistema de bacias tafrogênicas continentais do sudeste do Brasil -Revista Brasileira de Geociências, 15 (3): 193-201

Mizusaki, A.M.P.; Alves, D.B.; Conceição, J.C.J. 1994. Eventos magmáticos nas bacias do Espírito Santo, Mucuri e Cumuruxatiba. In: SBG, Congresso Brasileiro de Geologia, 38, Camburiú, SC, Geologia Estrutural e Tectônica de Bacias Sedimentares, 566-568

Mizusaki, A.M.P.; Mohriak, W.U. 1992. Sequências vulcano-sedimentares na região da plataforma continental de Cabo Frio, RJ. In: SBG, Congresso Brasileiro de Geologia 37, São Paulo, Anais, Resumos expandidos, 2:468-469

Mohriak, W.U.; Barros, A.Z.; Fujita, A.M. 1990. Magmatismo e tectonismo cenozóico na região de Cabo Frio, RJ. In: SBG, Congresso Brasileiro de Geologia, 36, Natal, RN, 6: $2873-2885$

Mohriak, W.U.; Sad, A.R.E.; Latgé, M.A.; Reis, A. P. 1991. Integração das folhas geológicas 1:50.000 do Estado do Rio de Janeiro, Relatório e Atlas Interno Petrobrás, Depex/Dirsul/Serab, 214-220

Ribeiro-Filho, E.; Cordani, U.G. 1966. Contemporaneidade das intrusões de rochas alcalinas do Itatiaia, Passa Quatro e Morro Redondo. Publ. $n^{\circ}, l$ do Núcleo do Rio de Janeiro, Sociedade Brasileira de Geologia, 62-63

Riccomini, C.; Melo, M.S.; Almeida, F.F.M.; Carneiro, C.D.R.; Mioto, J.A.; Hasui, Y. 1983. Sobre a ocorrência de um derrame de ankaramito na Bacia de Volta Redonda (RJ) e sua importância na datação das bacias tafrogênicas continentais do sudeste brasileiro. In: SBG, Simpósio Regional de Geologia, 4, São Paulo, Resumos. 23-24

Riccomini, C.; Peloggia, A.U.G.; Saloni, J.C.L.; Kohnk, M.W.; Figueira, R.M. 1989. Neotectonic activity in the Serra do Mar rift system (southeastern Brazil). Journal of South American Earth Sciences. 2 (2): 191-197 Riccomini, C.; Mello, M.S.;

Coutinho, J.M.V. 1991. Late Cretaceous-Early Tertiary ultrabasic magmatism in the western part of the state os Rio de Janeiro, Brazil. Boi. IG-USP, Publ.Esp., 10: 77-84;

Rodrigues, F.B.H.; Klein, V.C.; Cunha, F.L.S. 1982. Novas descobertas de rochas alcalinas na bacia de São José, Itaboraí, Rio de Janeiro. In: SBG, Congresso Brasileiro de Geologia, 33, Rio de Janeiro, Anais, 11: 4335-4339

Sonoki, I.K.; Garda, G.M. 1988. Idades K-Ar de rochas alcalinas do Brasil Meridional e Paraguai Oriental: compilação e adaptação às novas constantes de decaimento. Boi. IG-USP, Série Cientifica, 19: 63-85

Sadowski, G.R.; Dias Neto, C. de M. 1981.0 Lineamento Tectônico de Cabo Frio. Revista Brasileira de Geociências, 11 (4): 209-212

Skinner, B.J.; Porter, S.C. 1992. The Dynamic Earth -An Introduction to Physical Geology. 2 ed. John Wiley \& Sons, Inc., 570 p.

Szatmari, P.; Mohriak, W.U. 1995. Plate model of post-breakup tectono-magmatic activity in SE Brasil and the adjacent Atlantic. In: V Simp. Nac. de Estudos Tectônicos, 213-214

Vieira, J.C.; Dias, J.L.; Catto, A.J. 1987. Evolução estrutural da fase rifte da Bacia de Campos. In: Semin. Tect. Petrobrás, Tectos 1, Rio de Janeiro, Atas, 1: 488-500 